\title{
Construction and Performance Characteristics of New Fentanyl-Selective Plastic Membrane Electrode
}

\author{
Li Juan Peng, Meng Liang Wen, ${ }^{\dagger}$ and Yun YaO \\ Department of Chemistry, Yunnan University, Kunming, Yunnan 650091, PR China
}

\begin{abstract}
The construction and performance characteristics of an ion-selective electrode for fentanyl-drug cation, based on an ionpair complex with tetrakis[3,5-bis-(trifluoromethyl)phenyl]borate anion in a PVC matrix were studied. A linear response for $1 \times 10^{-5} \mathrm{~mol} \mathrm{dm}^{-3}$ to $1 \times 10^{-2} \mathrm{~mol} \mathrm{dm}^{-3}$ drug with a slope of $57.9 \pm 0.5 \mathrm{mV} /$ decade was established. The optimum $\mathrm{pH}$ range was 2 to 6 . The lower detection limit was $6.29 \times 10^{-6} \mathrm{~mol} \mathrm{dm}^{-3}$ fentanyl citrate $\left(2.1165 \mu \mathrm{g} \mathrm{cm}^{-3}\right.$ fentanyl). There were negligible interferences from a number of inorganic cations, structural analogues, and some common drug additives in injections. The electrode proposed has been successfully applied to determine fentanyl citrate in injections. The results correlated well with those obtained by the United States Pharmacopoeia standard procedure.
\end{abstract}

(Received February 19, 2001; Accepted April 25, 2001)

\section{Introduction}

Fentanyl, $N$-(1-phenethyl-4-piperidyl)propionanilide (Fig. 1), is a synthetic opiate analgesic, which is 50 to 100 times more potent than morphine. It acts in the central nervous system to relieve pain and is widely used in surgical anesthesia as the citrate salt at doses ranging from 2 to $50 \mu \mathrm{g} / \mathrm{kg}$. Meanwhile, fentanyl is also an analogue of illicit drugs, such as heroine, and is highly addictive for abusers. It is significantly more potent than heroine $(\sim 40 \times)$. It has been sold on the street as heroine, causing some deaths. Illicit use of pharmaceutical fentanyls first appeared in the mid-1970s in the medical community and continues to be a problem in the United States of America. Therefore, various methods have been developed for its quantitative determination: e.g., radioimmunoassay, ${ }^{1-5,11,16,28}$ radioreceptor assay, ${ }^{6-8}$ enzyme-linked immunosorbent assay, ${ }^{9-13}$ fluoroimmunoassay, ${ }^{14}$ gas chromatography, ${ }^{15-20}$ capillary gas chromatography, ${ }^{21-23}$ gas chromatography-mass spectrometry, ${ }^{4,21,24-28}$ thin-layer chromatography, ${ }^{26}$ gas liquid chromatography, ${ }^{29}$ high-performance liquid chromatography, ${ }^{30-36,38}$ micellar electrokinetic capillary chromatography, ${ }^{37}$ and electroencephalography, ${ }^{38}$ etc., all with the disadvantage of tedious sample preparation.

Potentiometric methods with ion-selective membrane electrodes can provide valuable means of monitoring fentanyl in pharmaceutical preparations because of their low cost, ease of use and maintenance, and the simplicity and speed of assay procedure. Although ion-selective membrane electrodes (ISME) have been widely used in pharmaceutical analysis, ${ }^{39-42}$ no electrodes responsive to fentanyl have so far been described. For this reason, we decided to investigate the response characteristics of a poly(vinyl chloride) membrane electrode with dibutyl phthalate as plasticizer based on fentanyltetrakis[3,5-bis(trifluoromethyl)phenyl]borate ion-pair complex for the determination of fentanyl citrate in injections. The

$\doteqdot$ To whom correspondence should be addressed.

E-mail: mlwen@ynu.edu.cn results agreed fairly well with those obtained by the United States Pharmacopoeia (USP) standard procedure. ${ }^{43}$

\section{Experimental}

\section{Reagents}

All chemicals were of analytical reagent grade and solutions were prepared with deionized water (conductivity $>1 \mu \mathrm{S} \mathrm{cm}^{-1}$ ). Potassium tetrakis[3,5-bis(trifluoromethyl)phenyl]borate and poly(vinyl chloride) (PVC, high molecular weight) were obtained from Fluka, dibutyl phthalate (DBP) from Sigma, tetrahydrofuran (THF), ammonium acetate, methanol, acetonitrile, and glacial acetic acid were from local chemical suppliers. The fentanyl citrate reference standard was obtained from the National Anesthesia Drug Laboratory, Beijing, PR China. Its characteristic was consistent with the USP. ${ }^{43}$ The fentanyl citrate injections $\left(0.1 \mathrm{mg} / 2 \mathrm{~cm}^{3}\right)$ were supplied by the Hubei Yiyao Ltd. Co., Hubei, PR China. A $1 \times 10^{-2} \mathrm{~mol} \mathrm{dm}^{-3}$ fentanyl citrate stock solution was prepared by dissolving $2.6431 \mathrm{~g}$ of pure anhydrous fentanyl citrate reference standard in $500 \mathrm{~cm}^{3} 0.1 \mathrm{~mol} \mathrm{dm}^{-3}$ citrate-NaOH buffer $(\mathrm{pH} \mathrm{4.0)}$. By appropriate dilution with the citrate- $\mathrm{Na}_{2} \mathrm{HPO}_{4}$ buffer, a series of standard solutions in the concentration range $1 \times 10^{-7} \mathrm{~mol} \mathrm{dm}^{-3}$ to $1 \times 10^{-3} \mathrm{~mol} \mathrm{dm}^{-3}$ were obtained.
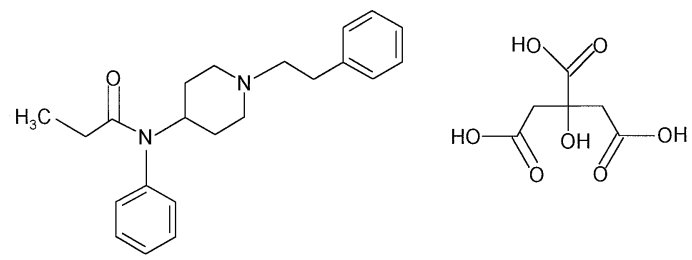

Fig. 1 The structure of fentanyl citrate. $\mathrm{C}_{22} \mathrm{H}_{28} \mathrm{~N}_{2} \mathrm{O} \cdot \mathrm{C}_{6} \mathrm{H}_{8} \mathrm{O}_{7}$, Mol Wt. 528.61. 
Table 1 Response characteristics of the fentanyl-selective PVC membrane electrode based on fentanyl-tetrakis[3,5bis(trifluoromethyl)phenyl]borate ion-pair complex with DBP plasticizer

\begin{tabular}{ll}
\hline \multicolumn{1}{c}{ Parameter } & \multicolumn{1}{c}{ Response } \\
\hline Slope $(\mathrm{mV} / \mathrm{decade})^{\mathrm{a}}$ & $57.9 \pm 0.5$ \\
Intercept, $E(\mathrm{mV})^{\mathrm{b}}$ & $441.4 \pm 1.3$ \\
Correlation coefficient, $r$ & 0.9979 \\
Linear range $\left(\mathrm{mol} \mathrm{dm}^{-3}\right)$ & $1 \times 10^{-5}-1 \times 10^{-2}$ \\
Lower detection limit $\left(\mathrm{mol} \mathrm{dm}^{-3}\right)$ & $6.29 \times 10^{-6}$ \\
\hline
\end{tabular}

Measurements were made in $0.1 \mathrm{~mol} \mathrm{dm}{ }^{-3}$ citrate- $\mathrm{NaOH}$ buffer at $\mathrm{pH}$ $4.0,25^{\circ} \mathrm{C}$.

a. Standard deviation of average slope values for multiple calibration $(n=45)$.

b. Standard deviation of values recorded over a period of 3 months ( $n$ $=45)$.

\section{Apparatus}

All EMF measurements were made with a pHS-3C Digital $\mathrm{pH}$ meter (Kai Li Scientific Instrument Ltd. Co., Xiaoshan, PR China). The external reference electrode was a Model 801 double-junction saturated calomel electrode with an outer bridge electrolyte (Jiangsu Electroanalytical Instrument Factory, Jiangsu, PR China). A Model 65-1 glass electrode (Kangling Optical \& Electrical Tech. Ltd. Co., Shanghai, PR China) was used for $\mathrm{pH}$ measurements.

ALC/GPC Model 201 HPLC (Waters, USA) and DL-800 Chromatographic Working Station (Dalian Elite Scientific Instruments Co. Ltd., Liaoning, PR China) were employed for the determination injections of fentanyl citrate by USP standard procedure. $^{43}$

\section{Construction of the electrode}

The fundamental principle of the fentanyl-selective membrane electrode construction has been described elsewhere. The PVCmembrane composition was $2.0 \%$ w/w tetrakis[3,5bis(trifluoromethyl)phenyl]borate, $49.0 \% \mathrm{w} / \mathrm{w}$ plasticizer and $49.0 \% \mathrm{w} / \mathrm{w}$ PVC. ${ }^{44-46}$ The electrode body was filled with a $10^{-4}$ mol dm ${ }^{-3}$ fentanyl citrate solution of $\mathrm{pH} 4.0$ (citrate- $\mathrm{NaOH}$ buffer solution, saturated with $\mathrm{AgCl}$ ), and the inner reference electrode was $\mathrm{Ag} / \mathrm{AgCl}$. The electrode was pre-conditioned for $24 \mathrm{~h}$ by soaking it in a $10^{-2} \mathrm{~mol} \mathrm{dm}^{-3}$ fentanyl citrate solution. Fentanyl cation reacted with tetrakis[3,5bis(trifluoromethyl)phenyl]borate to form stable ion-pair complexes within the membrane. Each complex was obtained in situ by soaking the PVC membrane in $10^{-2}$ mol dm${ }^{-3}$ fentanyl citrate solution. The electrode should be washed with deionized water before measurement. It could be kept in air when continuously used. The inner filling solution should be removed when not in use for a long time. All potentiometric measurements were performed using the following cell assembly: $\mathrm{Hg} / \mathrm{Hg}_{2} \mathrm{Cl}_{2} \mid \mathrm{KCl}$ (satd.) || salt bridge \| sample solution | membrane | $10^{-4} \mathrm{~mol} \mathrm{dm}^{-3}$ fentanyl citrate || $\mathrm{Ag} / \mathrm{AgCl}$. The electrode was washed with deionized water and blotted with tissue paper between measurements.

\section{Standard preparation}

We dissolved an accurately weighed quantity of fentanyl citrate reference standard in deionized water, and diluted it quantitatively with deionized water to obtain a solution having a known concentration of about $80 \mu \mathrm{g} \mathrm{cm}^{-3}{ }^{33}$

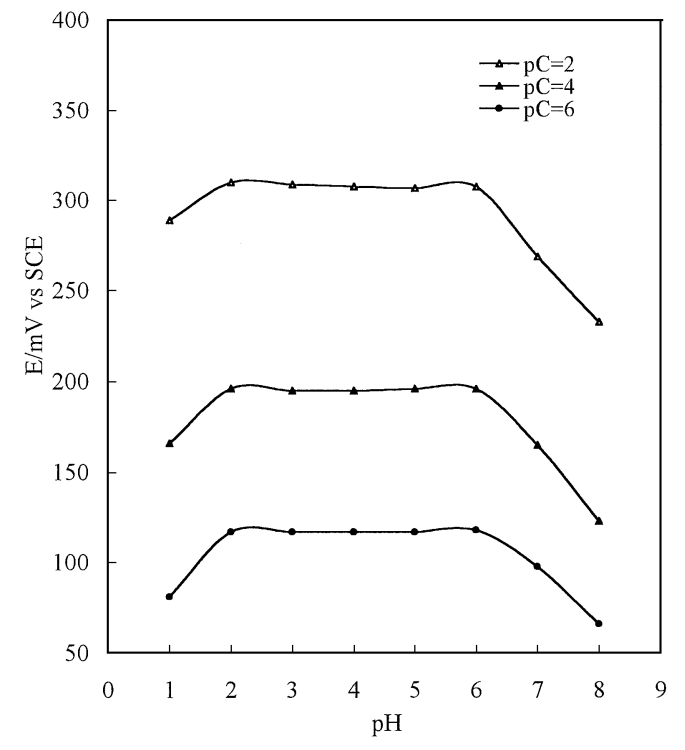

Fig. 2 Effect of $\mathrm{pH}$ on the response of the PVC fentanyl-selective membrane electrode based on fentanyl-tetrakis[3,5bis(trifluoromethyl)phenyl]borate ion-pair complex for $1 \times 10^{-6} \mathrm{~mol}$ $\mathrm{dm}^{-3}, 1 \times 10^{-4} \mathrm{~mol} \mathrm{dm}{ }^{-3}, 1 \times 10^{-2} \mathrm{~mol} \mathrm{dm}{ }^{-3}$ fentanyl citrate solutions.

\section{Assay preparation of injection}

We diluted the injection with deionized water so that each $\mathrm{cm}^{3}$ contained the equivalent of about $50 \mu \mathrm{g}$ of fentanyl. ${ }^{43}$

\section{Direct potentiometry}

Aliquots of $10 \mathrm{~cm}^{3}$ of $1 \times 10^{-7} \mathrm{~mol} \mathrm{dm}^{-3}$ to $1 \times 10^{-2} \mathrm{~mol} \mathrm{dm}^{-3}$ fentanyl citrate standard solutions were transferred into $25 \mathrm{~cm}^{3}$ beakers. The PVC fentanyl-selective membrane electrode based on fentanyl-tetrakis[3,5-bis(trifluoromethyl)phenyl]borate ionpair complex in conjunction with a double-junction saturated calomel electrode were placed into well-stirred $10 \mathrm{~cm}^{3}$ volumes of standard solutions in the order of $1 \times 10^{-7} \mathrm{~mol} \mathrm{dm}^{-3}$ to $1 \times$ $10^{-2} \mathrm{~mol} \mathrm{dm}^{-3}$ and potentials were recorded. The measured potential was plotted against the logarithm of the fentanyl citrate concentration. With the mean potential of five measurements, the unknown concentration could be derived from the regression equation of the calibration graph.

\section{Standard addition method}

A PVC fentanyl-selective membrane electrode based on fentanyl-tetrakis[3,5-bis(trifluoromethyl)phenyl]borate ion-pair complex in conjunction with a double-junction saturated calomel electrode were immersed into a sample of $10 \mathrm{~cm}^{3}$ with unknown concentration ( $\mathrm{ca} \cdot 10^{-4} \mathrm{~mol} \mathrm{dm}^{-3}$ ) for $30 \mathrm{~s}$ and the equilibrium potential of $E_{1}$ was recorded. Then $0.1 \mathrm{~cm}^{3}$ of $1 \times$ $10^{-2} \mathrm{~mol} \mathrm{dm}^{-3}$ of fentanyl citrate standard was added into the testing solution and the equilibrium potential of $E_{2}$ was obtained after $30 \mathrm{~s}$. From the change of $\Delta E\left(E_{2}-E_{1}\right)$ one can determine the concentration of the testing sample. ${ }^{47}$

\section{HPLC measurement}

The USP measurement was performed with a Bondapak C18 column $(4.6 \times 250 \mathrm{~mm})$. Equal volumes (about $\left.25 \mathrm{~mm}^{3}\right)$ of the standard preparation and the assay preparation of injection were injected into the chromatograph separately. The chromatograms were recorded and the responses for the major peaks were measured. The quantity, in $\mu \mathrm{g}$, of fentanyl $\left(\mathrm{C}_{22} \mathrm{H}_{28} \mathrm{~N}_{2} \mathrm{O}\right)$ in each $\mathrm{cm}^{3}$ of the injection was calculated by the formula: 
Table 2 Potentiometric selectivity coefficients $K_{\mathrm{I}, \mathrm{J}}^{\mathrm{Pot}}$ for the PVC fentanyl-selective membrane electrode with DBP plasticizer

\begin{tabular}{llll}
\hline \multicolumn{1}{c}{ Interferent } & \multicolumn{1}{c}{$K_{\mathrm{I}, \mathrm{J}}^{\text {Pot }}$} & \multicolumn{1}{c}{ Interferent } & \multicolumn{1}{c}{$K_{\mathrm{I}, \mathrm{J}}^{\text {Pot }}$} \\
\hline $\mathrm{NaHSO}_{3}{ }^{\mathrm{a}}$ & $1.08 \times 10^{-2}$ & DL-Alaninee & $1.26 \times 10^{-2}$ \\
$\mathrm{Na}_{2} \mathrm{CO}_{3}{ }^{\mathrm{b}}$ & $5.62 \times 10^{-3}$ & Potassium oxalate $^{\mathrm{f}}$ & $5.41 \times 10^{-3}$ \\
Benzoic acid $^{\mathrm{b}}$ & $8.26 \times 10^{-3}$ & $\mathrm{NaCl}^{\mathrm{g}}$ & $7.20 \times 10^{-2}$ \\
Picric acid $^{\mathrm{c}}$ & $7.13 \times 10^{-3}$ & Thebaine $^{\mathrm{g}}$ & $2.58 \times 10^{-1}$ \\
$\left(\mathrm{NH}_{4}\right)_{2} \mathrm{SO}_{4}{ }^{\mathrm{c}}$ & $5.01 \times 10^{-3}$ & Caffeine $^{\mathrm{g}}$ & $8.64 \times 10^{-3}$ \\
$\mathrm{Hg}^{\mathrm{N} O} \mathrm{NO}_{3}{ }_{2}{ }^{\mathrm{c}}$ & $2.14 \times 10^{-4}$ & Cinchonine $^{\mathrm{g}}$ & $7.70 \times 10^{-2}$ \\
Urea $^{\mathrm{d}}$ & $7.69 \times 10^{-3}$ & Theophylline $^{\mathrm{g}}$ & $8.63 \times 10^{-3}$ \\
Glucose $^{\mathrm{d}}$ & $8.33 \times 10^{-3}$ & Morphine $\mathrm{HCl}^{\mathrm{g}}$ & $7.72 \times 10^{-3}$ \\
DL-Cystine $^{\mathrm{e}}$ & $1.07 \times 10^{-2}$ & Procaine $^{\mathrm{g}}$ & $2.67 \times 10^{-2}$ \\
\hline
\end{tabular}

The concentrations of fentanyl citrate and the interferents were kep at a level of $1 \times 10^{-3} \mathrm{~mol} \mathrm{dm}^{-3}$ in solutions of the same $\mathrm{pH}$ and ionic strength $\left(0.1 \mathrm{~mol} \mathrm{dm}^{-3}\right.$ citrate-NaOH buffer of $\left.\mathrm{pH} 4.0\right)$ at $25^{\circ} \mathrm{C}$.

a. Anti-oxidants in the normal injections.

b. Preservative agents in the normal injections.

c. Precipitating agents of sample preparation.

d. Endogenous substances of urine.

e. Amino acids.

f. Anticoagulants of blood sample preparation.

g. Structural analogues

\section{$(336.48 / 528.61) C D\left(r_{\mathrm{u}} / r_{\mathrm{s}}\right)$,}

in which 336.48 and 528.61 are the molecular weights of fentanyl and fentanyl citrate, respectively; $C$ is the concentration in $\mu \mathrm{g}$ per $\mathrm{cm}^{3}$ of fentanyl citrate reference standard in the standard preparation; $D$ is the dilution factor used to obtain the assay preparation; and $r_{\mathrm{u}}$ and $r_{\mathrm{s}}$ are the peak responses for the fentanyl peak obtained from the assay preparation and the standard preparation, respectively. ${ }^{43}$

\section{Results and Discussion}

The critical response characteristics of a fentanyl-selective PVC membrane electrode based on fentanyl-tetrakis[3,5bis(trifluoromethyl)phenyl]borate with DBP plasticizer at $25^{\circ} \mathrm{C}$ are given in Table 1. Calibrations were made at a constant $\mathrm{pH}$ and ionic strength using $0.1 \mathrm{~mol} \mathrm{dm}^{-3}$ citrate- $\mathrm{NaOH}$ buffer $(\mathrm{pH}$ 4.0). The electrode displayed a linear response for aqueous fentanyl citrate solutions over the concentration range of $1 \times$ $10^{-5} \mathrm{~mol} \mathrm{dm}^{-3}$ to $1 \times 10^{-2} \mathrm{~mol} \mathrm{dm}{ }^{-3}$. The calibration slopes were $57.9 \pm 0.5 \mathrm{mV}$. The lower detection limit observed for the fentanyl-selective membrane electrodes based on fentanyltetrakis[3,5-bis(trifluoromethyl)phenyl]borate was determined according to the IUPAC recommendations and was found to be $6.29 \times 10^{-6} \mathrm{~mol} \mathrm{dm}^{-3}$ fentanyl citrate $\left(2.1165 \mu \mathrm{g} \mathrm{cm}^{-3}\right.$ fentanyl). ${ }^{47}$ The potential readings were stable and consistent to $\pm 1.1 \mathrm{mV}$ within the same day and were reproducible to within $\pm 1.6 \mathrm{mV}$ in a $1 \times 10^{-4} \mathrm{~mol} \mathrm{dm}^{-3}$ fentanyl citrate solution for $4 \mathrm{~h}$ continuous use. The stability of the electrode response was checked over a period of 3 months. The time required for the electrode to reached $95 \%$ of final response was less than $30 \mathrm{~s}$. The electrode response displayed good stability and reproducibility over the test, as shown by the relative standard deviation values in Table 1.

The $\mathrm{pH}$ dependence of the potentials of the electrode was investigated by observing the changes in the potential readings with $\mathrm{pH}$ of the unbuffered solutions $\left(1 \times 10^{-6} \mathrm{~mol} \mathrm{dm}^{-3}-1 \times\right.$ $10^{-2} \mathrm{~mol} \mathrm{dm}^{-3}$ fentanyl citrate solution) after addition of small
Table 3 Comparison of mean values of potentiometric method and USP standard method for the assay of fentanyl citrate in injection

\begin{tabular}{cccccc}
\hline \multirow{2}{*}{$\begin{array}{c}\text { Sample } \\
\left(0.1 \mathrm{mg} / 2 \mathrm{~cm}^{3}\right)\end{array}$} & \multicolumn{2}{c}{ Potentiometric method } & & \multicolumn{2}{c}{ USP standard method } \\
\cline { 6 - 6 } \cline { 5 - 6 } & Recovery $^{\mathrm{a}}$ & $\mathrm{RSD}, \%$ & & Recovery $^{\mathrm{a}}$ & $\mathrm{RSD}, \%$ \\
\hline 1 & 98.27 & 1.05 & & 98.16 & 0.67 \\
2 & 98.84 & 0.83 & & 99.07 & 0.81 \\
3 & 99.47 & 1.09 & & 98.66 & 0.75 \\
4 & 98.95 & 1.08 & & 98.69 & 0.71 \\
5 & 100.53 & 1.01 & & 99.85 & 0.88 \\
\hline
\end{tabular}

a. $\%$ of nominal value. All values were the average of 5 determinations.

volumes of $3 \mathrm{~mol} \mathrm{dm}{ }^{-3} \mathrm{HCl}$ and/or $3 \mathrm{~mol} \mathrm{dm}^{-3} \mathrm{NaOH}$. It was found that the fentanyl-sensitive membrane electrode based on fentanyl-tetrakis[3,5-bis(trifluoromethyl)phenyl]borate ion-pair complex showed virtually no $\mathrm{pH}$ response over the range of $2.0-6.0 \mathrm{pH}$ units (Fig. 2). That means the protonation form of fentanyl could be maintained in the range of $2.0-6.0 \mathrm{pH}$ units. Decrease in the potentials above $\mathrm{pH} 6.0$ would be presumably due to the formation of the deprotonated fentanyl species and precipitation of free fentanyl base in the test solutions, which were not sensed by the electrode.

The potentiometric selectivity coefficient defines the ability of an ion-selective electrode to distinguish a particular ion from others. It is one of the most important characteristics of an ionselective electrode, as it often determines whether a reliable measurement in the target sample is possible. If one considers the further utilization of the fentanyl-selective PVC membrane electrode in analyzing biological sample, such as urine and blood, some substances which might exist in the procedure of the sample preparation were selected. The interferences of common inorganic cations, antioxidants and preservative agents in the normal injections, precipitating agents of sample preparation, endogenous substances of urine, amino acids, anticoagulants of blood sample preparation, and some structural analogues on selectivity of proposed electrode were studied by the separated solution method (SSM) recommended by the IUPAC. ${ }^{47}$ The concentrations of fentanyl citrate and the interferents were kept at a level of $1 \times 10^{-3} \mathrm{~mol} \mathrm{dm}^{-3}$ in solutions of the same $\mathrm{pH}$ and ionic strength $\left(0.1 \mathrm{~mol} \mathrm{dm}^{-3}\right.$ citrate- $\mathrm{NaOH}$ buffer of $\mathrm{pH} 4.0$ ) at $25^{\circ} \mathrm{C}$. The potentiometric selectivity coefficients $\left(K_{\mathrm{I}, \mathrm{J}}^{\mathrm{Pot}}\right)$ listed in Table 2 show that the proposed electrode exhibited reasonable selectivity towards fentanyl citrate. There was no significant interference from most of the tested substances, with the exception of thebaine that caused slight interference.

The proposed electrode was employed for the assay of the fentanyl citrate content in injections by the standard addition method. The results of the potentiometric methods compared with the USP standard procedure are shown in Table 3. These results correlated well with those obtained by the USP standard procedure

In conclusion, the fentanyl-selective PVC membrane electrode based on fentanyl-tetrakis[3,5-bis(trifluoromethyl)phenyl]borate ion-pair complex exhibited useful analytical characteristics for the determination of fentanyl citrate in pharmaceutical preparations. 


\section{Acknowledgements}

The authors gratefully acknowledge the support from the Natural Science Fund of Yunnan and the Science Fund of Yunnan Education Department.

\section{References}

1. W. E. Woods, H. H. Tai, C. Tai, T. Weckman, T. Wood, H. Barios, J. W. Blake, and T. Tobin, Am. J. Vet. Res., 1986, 47, 2180.

2. R. L. Sliller, A. M. Scierka, P. J. Davis, and D. R. Cook, Forensic Sci. Int., 1990, 44, 1.

3. G. L. Henderson, M. R. Harkey, and A. D. Jones, J. Anal. Toxicol., 1990, 14, 172.

4. V. W. Watts and Y. H. Caplan, J. Anal. Toxicol., 1990, 14, 266.

5. W. L. Wang, E. J. Cone, and J. Zacny, Forensic Sci. Int., 1993, 61, 65

6. V. Levi, J. C. Scott, P. F. White, and W. Sadee, Pharm. Res., 1987, 4, 46.

7. M. E. Alburges, G. R. Hanson, J. W. Gibb, C. O. Sakashita, and D. E. Rollins, J. Anal. Toxicol., 1991, 15, 311.

8. M. E. Alburges, G. R. Hanson, J. W. Gibb, C. O. Sakashita, and D. E. Rollins, J. Anal. Toxicol., 1992, 16, 36.

9. T. Tobin, H. H Tai, C. L. Tai, P. K. Houtz, M. R. Dai, W. E. Woods, J. M. Yang, T. J. Weckman, and S. L. Chang, Res. Commun. Chem. Pathol. Pharmacol., 1988, 60, 97.

10. F. T. Delbeke and M. Debackere, J. Vet. Pharmacol. Ther., 1989, $12,1$.

11. T. Tobin, S. Kwiatkowski, D. S. Watt, H. H. Tai, C. L. Tai, W. E. Woods, J. P. Goodman, D. G. Taylor, and T. J. Weckman, Res. Commun. Chem. Pathol. Pharmacol., 1989, 63, 129.

12. W. Ruangyuttikarn, M. Y. Law, and D. E. Rollins, J. Anal. Toxicol., 1990, 14, 160.

13. G. S. Makowski, J. J. Richter, R. E. Moore, R. Eisma, D. Ostheimer, M. Onoroski, and A. H. Wu, Ann. Clin. Lab. Sci., 1995, 25, 169.

14. J. McDonald, R. Gall, P. Wiedenbach, V. D. Bass, B. Deleon, C. Brockus, D. Stobert, S. Wie, and C. A. Prange, Res. Commun. Chem. Pathol. Pharmacol., 1987, 57, 389.

15. T. J. Gillespie, A. J. Gandolfi, R. M. Maiorino, and R. W. Vaughan, J. Anal. Toxicol., 1981, 5, 133.

16. R. J. H. Woestenborghs, D. A. Stanski, J. C. Scott, and J. J. P. Heykants, Anesthesiology, 1987, 67, 85.

17. S. Suzuki, H. Tsuchihashi, and H. Arimoto, J. Chromatogr., 1989, 475, 400.

18. P. Kintz, P. Mangin, A. J. Lugnier, and A. A. Chaumont, J. Chromatogr., 1989, 489, 459.

19. A. Szeitz, K. W. Riggs, and C. Harvey-Clark, J. Chromatogr. B: Biomed. Appl., 1996, 675, 33.

20. H. Ohta, S. Suzuki, and K. Ogasawara, J. Anal. Toxicol., 1999, 23, 280.
21. V. Watts and Y. Caplan, J. Anal. Toxicol., 1988, 12, 246.

22. S. Bjokman and D. R. Stanski, J. Chromatogr., 1988, 433, 95.

23. P. Kintz, A. Tracqui, A. J. Lungnier, P. Mangin, and A. A. Chaumont, Methods Find. Exp. Clin. Pharmacol., 1990, 12, 193.

24. S. N. Lin, T. P. Wang, R. M. Caprioli, and B. P. Mo, J. Pharm. Sci., 1981, 70, 1276.

25. T. Goromaru, H. Matsuura, N. Yoshimura, T. Miyawaki, T. Sameshima, J. Miyao, T. Furuta, and S. Baba, Anesthesiology, 1984, 61, 73.

26. P. Lillunde and T. Korte, J. Anal. Toxicol., 1991, 15, 71.

27. D. P. Kingsbury, G. S. Makowski, and J. A. Stone, J. Anal. Toxicol., 1995, 19, 27.

28. B. Fryirsa, A. Woodhouse, J. L. Huang, M. Dawsen, and L. E. Mather, J. Chromatogr., B: Biomed. Appl., 1997, 688, 79.

29. S. R. Kowalski, G. K. Gourlay, D. A. Cherry, and C. F. McLean, J. Pharmacol. Methods, 1987, 18, 347.

30. K. Kumar, D. J. Morgan, and D. P. Crankshaw, J. Chromatogr., 1987, 419, 464.

31. T. D. Wilson, T. Maloney, and W. B. Amsden, J. Chromatogr., 1988, 445, 299.

32. M. Tsuchiya, W. Ueda, M. Tomoda, and M. Hirakawa, Masui, 1991, 40, 644.

33. W. M. Dewell, M. Khandaghabadi, M. J. D'souza, and H. M. Solomon, Am. J. Hosp. Pharm., 1993, 50, 2374.

34. K. Kumar, J. A. Ballantyne, and A. B. Baker, J. Pharm. Biomed. Anal., 1996, 14, 667.

35. E. J. Portier, K. de Blok, J. J. Butter, and C. J. van Boxtel, J. Chromatogr. B: Biomed. Sci. Appl., 1999, 723, 313.

36. J. Lambropoulos, G. A. Spanos, N. V. Lazaridis, T. S. Ingallinera, and V. K. Rodriguez, J. Pharm. Biomed. Anal. 1999, 20, 705 .

37. R. Weinberger and I. S. Lurie, Anal. Chem., 1991, 63, 823.

38. J. C. Scott, K. V. Ponganis, and D. R. Stanski, Anesthesiology, 1985, 62, 234.

39. V. V. Cosofret, Tr. Anal. Chem., 1991, 10, 298

40. V. V. Cosofret and R. P. Buck, "Pharmaceutical Applications of Membrane Sensors", 1992, CRC Press, Boca Raton.

41. V. V. Cosofret and R. P. Buck, Crit. Rev. Anal. Chem., 1993, 24,1 .

42. R.-I. Stefan, G.-E. Baiulescu, and H. Y. Aboul-Enein, Crit. Rev. Anal. Chem., 1997, 27, 307.

43. United States Pharmacopoeia, 1995, Vol. XXIII, US Pharmacopoeial Convention Inc., Rockville, MD, 654 655.

44. A. Craggs, G. L. Moody, and J. D. R. Thomas, J. Chem. Edu., 1974, 51, 541.

45. C. R. Martin and H. Fresier, Anal. Chem., 1980, 52, 562.

46. V. V. Cosofret and R. P. Buck, Anal. Chim. Acta, 1984, 174, 299.

47. R. P. Buck and E. Lindner, Pure Appl. Chem., 1994, 66, 2527. 